\title{
Welcome Associate Editor Zsolt Balogh
}

\author{
John G. Hunter ${ }^{1}$
}

(C) Société Internationale de Chirurgie 2015

The World Journal of Surgery would like to welcome a new associate editor to our ranks. Zsolt Balogh MD PhD FRACS (ortho), F. A. Orth. A., FACS is the Director of Trauma at the John Hunter Hospital and Professor of Surgery and Traumatology at the University of Newcastle in Newcastle, Australia. Prof Balogh was born in Hungary and is a dual citizen of Hungary and Australia. He received his MD and $\mathrm{PhD}$ at the Albert Szent-Gyorgyi Medical University in Szeged, Hungary, where he also received his clinical training in orthopedics and traumatology and then joined the faculty in the Department of Traumatology at the Albert Szent-Gyorgyi Medical Center for 5 years. Following this, he did several trauma fellowships in the US and Australia before joining the faculty in the John Hunter Hospital in Newcastle in 2005 as Director of the Trauma Services. He became the Professor of Traumatology in 2009 and the Professor of Surgery in Newcastle in 2015. He has received 22 awards for scholarly work, including the John Mitchell Crouch Fellowship, which is the most prestigious research recognition of the Royal Australasian College of Surgeons. His students, residents, and fellows have received an additional 16 awards. His paper entitled "Epidemiology of Traumatic Deaths: Comprehensive Population Based Assessment" was awarded the WJS 2010 paper of the year. Prof Balogh has received 14 research grants to cover everything from basic science in trauma and inflammation to public health. He has published 150 peer review manuscripts, many in the WJS, and has guest edited a symposium for the WJS on the abdominal compartment syndrome. He has served as a reviewer for the WJS since 2005 and has served on the editorial board since 2013. Prof Balogh has presented his research internationally and has held leadership positions in the Australian Orthopedic Association, The AO Foundation, the Royal Australasian College of Surgeons, the American Association for the Surgery of Trauma, and a number of other organizations. Prof Balogh will join Ari Leppaniemi as our WJS Associate Editors for the Surgery of Trauma, Critical Care, and Acute Care Surgery. We are thrilled to have the academic talents of Zsolt Balogh on our team of Associate Editors.

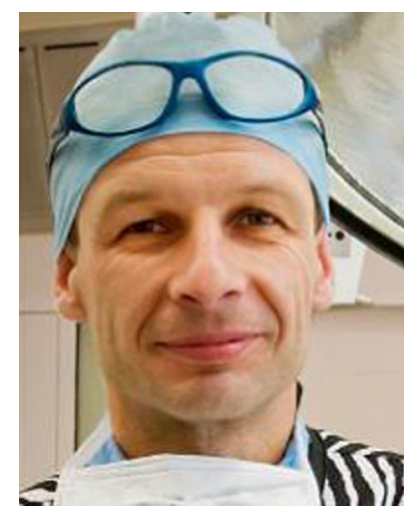

John G. Hunter

hunterj@ohsu.edu

1 Department of Surgery, Oregon Health and Science University School of Medicine, Portland, OR, USA 